\title{
Fortis-lenis distinction of fricatives and plosives in Welsh - Phonetically distinctive factors
}

\author{
Michał Baran \\ University of Szczecin, Poland
}

\begin{abstract}
This paper continues a research project aimed at proving that the fortis-lenis distinction is more appropriate for studying the Welsh language than the voiced-voiceless divide. Previous analyses of articulatory timing revealed potentially distinctive features characteristic for Welsh plosives and fricatives. Even though the phonological features such as [spread glottis] or [voice] may be used both for distinguishing between the series of plosives and fricatives, the phonetic features responsible for the distinction are likely to differ due to the different phonetic nature of the manner of articulation and the position of fricatives and plosives (Honeybone 2005: 333-334). The aim of this paper is, therefore, to draw general conclusions from analysing the two sets of factors and find some universal features or characteristics of fortis and lenis obstruents in Welsh. Based on the previous studies, the importance of aspiration and voicing length are analysed in Welsh plosives. For fricatives, friction and voicing length are studied as potentially contrastive. The main hypotheses are that (i) phonetic voicing is not decisive in distinguishing between the two series of sounds in all places of articulation and (ii) other aspects of articulatory timing such as friction, aspiration length and hold phase duration appear to be more important in the fortis-lenis distinction and form a general pattern where the fortis sounds are generally longer than their lenis counterparts.
\end{abstract}

Keywords: fortis-lenis distinction, plosives, fricatives, articulatory timing, laryngeal contrast

\section{Introduction}

Consonant distinctions are key in describing sound inventories of languages. They let researchers organise the sounds into groups based on common features. These features may generally belong to one of three groups: place of articulation, manner of articulation and laryngeal features. Laryngeal features constitute a laryngeal system of a given language, which is here understood as "the totality of phonological and phonetic aspects which are responsible for the observed phonetic facts, where phonology and phonetics are kept strictly apart, and yet they form two sides of the same coin" (Cyran 2011: 50). On one side of the coin there are phonological features responsible for the phonological distinction such as [spread glottis], [voice] or [constricted] and on the other, there are phonetic indicators of the aforementioned features. Most frequently, for instance, aspiration suggests the presence of the [spread glottis] 
factor and phonetic voicing indicates [voice]. This paper looks at laryngeal features used in the analysis of the Welsh plosives and fricatives. There are three main treatments of the laryngeal features in Welsh as far as the aforementioned groups of sounds are concerned. Firstly, there is an approach which divides plosives and fricatives into two series, i.e. voiceless and voiced (Ball and Williams 2001). In such an approach, it naturally follows that the Welsh language exhibits [voice] as a distinctive feature, but this is not confirmed by experimental phonetics (Asmus and Grawunder 2017, Ball 1984, Jones 1984). The second approach employs the terms fortis and lenis as a phonological distinction that may be based on other features than [voice] and as a result appears to solve the main issue of the voiced-voiceless approach (Hannahs 2013; Ball 1984; Cyran 2011). However, if fortis and lenis are used as synonyms of voiceless and voiced, i.e. when the authors present the same minimal pairs and oppositions as in the voiceless-voiced distinction, such account fails to explain certain phenomena found in the Welsh language, most importantly morpheme-initial consonant mutations. Therefore, the third approach, advocated in this paper, views the fortis-lenis divide as phonologically separate from the voiceless-voiced distinction in that it results in a different division of the phonemes rendering different groups of sounds and considering different minimal pairs vital. This perspective seems to be supported by morphophonological and phonological analyses (see for example Baran and Asmus 2019), but also by experimental phonetics (Asmus et al. 2019). If the phonological fortis-lenis distinction is to be seen as one side of the coin of the Welsh laryngeal system, the other side of the coin, i.e. the phonetic factors responsible for that distinction have to be experimentally verified.

The aim of this paper is to summarise what has currently been achieved in the research project aimed at identifying the phonetic correlates of the fortis-lenis distinction in Welsh. Two studies, one on plosives (Asmus et al. 2019) and the other on fricatives (Baran 2020), are presented and the findings are compared in order to contribute to the debate focused on whether the fortis-lenis distinction hinges on the same or comparable phonetic features for both fricatives and plosives. The influence of voicing, so important in the voiceless-voiced distinction, is compared with the influence of alternative features such as aspiration and friction for plosives and fricatives respectively in order to show that for the fortis-lenis distinction, phonetic voicing is at most of minor importance.

\section{Theoretical background of the study}

\subsection{Overview of research of laryngeal distinctions}

The aim of this section is to present some examples of studies on laryngeal system organisation in order to show that despite various approaches to this issue there seems to be an agreement regarding the fact that the voiceless-voiced distinction, despite being quite wide-spread, is not the only possibility and is not always synonymous with the fortis-lenis distinction. This paper does not exclusively follow any of the approaches below but favours an eclectic approach.

Jakobson, Fant and Halle (1951) mention two most important laryngeal distinctions, namely between tense and lax consonants (and vowels) and voiceless and voiced consonants 
(and potentially vowels). They see "the superposition of a harmonic sound source upon the noise structure" as the main indicator of the voiceless-voiced distinction (Jakobson, Fant and Halle 1951: 26). According to these authors, the tense-lax distinction is said to rely upon two features namely the length of the sound interval and articulatory energy with the tense sounds exhibiting a longer sound interval and a higher level of articulatory energy resulting from a greater deformation of the vocal tract from its neutral position and longer articulation. Jakobson, Fant and Halle also acknowledge that the voiceless-voiced distinction is widespread in the world and that it may alternate with the tense-lax distinction in one of four ways, i.e. (i) coexist by being its concomitant, (ii) become redundant because the tense-lax distinction is more appropriate for a given language, (iii) be relevant for only some classes of consonants of a given language and (iv) be irrelevant for the language together with the tense-lax distinction.

The theory of laryngeal realism (Honeybone 2005) contributes to the debate on laryngeal systems by suggesting that there are languages for which (i) the feature [voice] is irrelevant and proves to be useless in descriptions of the diachrony of a language and its current state and processes, (ii) the feature [spread glottis] is more appropriate and enables researchers to explain previously puzzling processes. The phonological feature [voice] logically results in the voicelessvoiced distinction while [spread glottis] is associated with the fortis-lenis, or in Jakobson Fant and Halle's terms, tense-lax distinction. The languages employing the distinctions are also called voicing and aspirating languages respectively. Honeybone (2005) also argues that the features such as [voice] and [spread] are privative and that the unmarked series is non-specified, i.e. only the marked series is phonologically specified. ${ }^{1}$ Such claims lead to rather meaningful changes not only in phonological analyses, but they may even be used to justify changes to phonological symbols used. From this very radical point of view, Welsh plosives and fricatives would be organised in the following way:

(1) A. fortis $/ \mathrm{p}^{\mathrm{h}}, \mathrm{t}^{\mathrm{h}}, \mathrm{k}^{\mathrm{h}} / \mathrm{vs}$ lenis $/ \mathrm{p}^{\mathrm{o}}, \mathrm{d}^{\mathrm{o}}, \mathrm{g}^{\mathrm{o}} /$

B. fortis $/ \mathrm{f}^{\mathrm{h}}, \mathrm{s}^{\mathrm{h}}, \theta^{\mathrm{h}} / \mathrm{vs}$ lenis $/ \mathrm{f}^{\mathrm{o}}, \mathrm{h}^{\mathrm{o}}, \theta^{\circ} /$

This kind of notation stresses the fact that the series of sounds in (1) differ not in the [voice] feature, but in [spread glottis] with the fortis series being specified with it. In this paper, however, for the sake of clarity, the conventional notation is employed. It should be mentioned here that the minimal pairs in the description of the laryngeal system are not always the same as phonological minimal pairs in Welsh. In this paper, a phonological minimal pair is understood as one that is supported by the morpheme-initial consonant mutation system. The morpheme-initial consonant mutations may be defined as systematic and grammaticalised changes that affect morpheme-initial phonemes yielding those that are phonetically different (Asmus and Grawunder 2017: 22). The table below presents the paradigm of changes (for a more detailed analysis of mICM see Baran and Asmus 2019).

The notion of markedness is, however, not fully useful with languages such as Welsh, where sound changes form sequences such as $/ \mathrm{p} /->/ \mathrm{b} /->/ \mathrm{v} /$. 
Table 1: Morpheme-initial mutations in Welsh

\begin{tabular}{|c|c|c|c|}
\hline Radical & Lenition & Nasalisation & Spirantisation \\
\hline $\mathrm{p} / \mathrm{p}^{(\mathrm{h})} /$ & $\mathrm{b} / \mathrm{b}^{(\mathrm{h})} /$ & $\mathrm{mh} / \mathrm{m} /$ & $\mathrm{ph} / \mathrm{f} /$ \\
\hline $\mathrm{t} / \mathrm{t}^{(\mathrm{h})} /$ & $\mathrm{d} / \mathrm{d}^{(\mathrm{h})} /$ & $\mathrm{nh} / \mathrm{n} /$ & th $/ \theta /$ \\
\hline $\mathrm{c} / \mathrm{k}^{(\mathrm{h})} /$ & $\mathrm{g} / \mathrm{g}^{(\mathrm{h})} /$ & $\mathrm{ngh} / \mathrm{n} /$ & $\operatorname{ch} / x \mid$ \\
\hline $\mathrm{b} / \mathrm{b}^{(\mathrm{h})} /$ & $\mathrm{f} / \mathrm{v} /$ & $\mathrm{m} / \mathrm{m}, \mathrm{m} /$ & \\
\hline $\mathrm{d} / \mathrm{d}^{(\mathrm{h})} /$ & dd /ð/ & $\mathrm{n} / \mathrm{n}, \mathrm{n} /$ & \\
\hline $\mathrm{g} / \mathrm{g}^{(\mathrm{h})} /$ & $\varnothing$ & $\mathrm{ng} / \mathrm{y} /$ & \\
\hline $\mathrm{m} / \mathrm{m}^{(\mathrm{h})} /$ & $\mathrm{f} / \mathrm{v} /$ & & \\
\hline $11 / 1 /$ & $1 / 1, \mathrm{l} /$ & & \\
\hline $\mathrm{rh} / \mathrm{r} /$ & $\mathrm{r} / \mathrm{r} /$ & & \\
\hline
\end{tabular}

While in some cases, for instance in plosives, the pairs are the same as the ones present in the laryngeal system, in fricatives they are quite different. For instance, $/ \theta /$ and $/ ð /$ are definitely contrastive within the laryngeal system of Welsh as they are both interdental fricatives and differ only in the former being fortis and the latter lenis. However, in the morpheme-initial mutation system, the two sounds are not linked to each other as $/ \theta /$ is a spirantisation reflex of $/ \mathrm{t} /$ while $/ \partial /$ is a lenition reflex of $/ \mathrm{d} /$. Therefore, they are not considered phonologically contrastive to the same extent as minimal pairs such as $/ \mathrm{p} /$ and $/ \mathrm{b} /$.

Laryngeal realism advocated by Honeybone (2005) presupposes a direct link between certain phonetic aspects of a sound and its phonological specification. For instance, the presence of full voicing would mean that the sound is specified with [voice] and also that the language is a voicing language. As a result, the theory does not allow for much arbitrariness in linking phonetics to phonology. Cyran (2011) disagrees with such a point of view and introduces laryngeal relativism as an updated version of laryngeal realism. He claims that the aforementioned phonetic cues do not always indicate the same phonological features. Voicing, for instance, may be spontaneous, passive or active and only the last one is an indicative of the [voice] feature and the language having voiceless-voiced distinction. Such point of view would not change the way Welsh sounds are presented in (1) but would allow for some degree of arbitrariness while analysing their phonetic shape.

All the aforementioned theories are relevant to this paper as they confirm that there are various possible organisation patterns of laryngeal systems and it logically follows that a successful analysis of a given language requires applying the most appropriate laryngeal distinction. Understandably, there are also some differences between the approaches presented above, but as these differences are phonological in nature, they go beyond the scope of this paper.

Jaeger (1983) in a paper devoted to Zapotec and Jawoñ devotes some space to general considerations of the phonetic nature and application of the fortis-lenis distinction. His considerations are partly based on the paper by Jakobson, Fant and Halle, mentioned before. It is claimed that the fortis-lenis divide can be used either as a basic phonological divide for languages whose consonant series do not differ in terms of voicing or as an additional distinction, overlapping with and enriching the voiceless-voiced distinction. However, according to Jaeger, in languages such as English, where the feature fortis is used in analysis of the voiceless plosives because of their aspiration, the fortis-lenis distinction is seen to be 
redundant as the sounds are sufficiently distinguished on the basis of VOT which is not seen as a function of the fortis-lenis distinction by Jaeger. Four groups of potential phonetic correlates of the fortis-lenis distinction are mentioned, i.e. (1) pulmonic factors, (2) articulation factors, (3) timing factors and (4) glottal factors with groups (3) and (4) being of particular importance for this paper (see sections 2.3. and 3.1.).

Before finding the correlates, one would also have to decide whether there is a single phonetic factor to distinguish between the phonological series or whether the distinction is multifactorial. Butcher (2004) provides an overview of the most common approaches to this issue. Firstly, he points to the theories which claim that there is one single feature that differentiates between the fortis and lenis consonants. Physical effort in the form of muscular tension is claimed to be such a factor. This approach is practised for instance by Hardcastle (1973) and Ladefoged (1989). Secondly, there is an approach in which a combination of two factors is used to differentiate between the fortis and lenis consonants. These factors are glottal aperture and articulatory timing, whereas voicing and aspiration are not relevant. Such a view can be found in the works of Malecot (1970) and Stetson (1951). Finally, there is a theory on which the present research is based that considers the difference between the fortis and lenis series of sounds a combination of four parameters, namely: peak glottal aperture, articulatory timing, voicing and aspiration (see Asmus et al. 2019).

\subsection{Overview of research of laryngeal distinction of Welsh consonants}

Ball (1984) claims that (i) the voiceless-voiced distinction reflects the state of the glottis during the closure stage, (ii) the aspirated-unaspirated distinction refers to the state of the glottis during and after the release of the closure and (iii) the fortis-lenis distinction is seen as something related to the force of articulation and cannot be verified experimentally. This approach directly links certain articulatory aspects to specific distinctions, not allowing for much arbitrariness. Ball claims that both for stops and fricatives voicing is irrelevant in the initial position and may sometimes be relevant in the final position while distinguishing between the fortis and lenis series. He also states that other factors such as (i) VOT/aspiration for plosives, (ii) friction length for fricatives and (iii) preceding vowel length and quality offer considerably more conclusive marking of the fortis and lenis series. These results seem to confirm that Welsh is an aspirating language with a fortis-lenis distinction.

Jones (1984) is also interested in the laryngeal distinctions of Welsh obstruents. He focuses on stops and fricatives and omits affricates as they occur mainly in borrowings. As far as stops are concerned, he notices that the unaspirated plosives are not constantly voiced and that VOT is decisive in discriminating between the fortis and lenis series. He is also aware of potential differences in the force of articulation, but like Ball claims that there is no experimental justification. For fricatives, the same pairs of sounds as in Ball are analysed and Jones' findings are the same as Ball's as far as decisive factors are concerned.

Jones' paper would also support the idea that the Welsh obstruent inventory features a fortis-lenis distinction. However, even though both Ball (1984) and Jones (1984) employ the fortis-lenis distinction in individual sounds, it does not lead them to analyse pairs of sounds contrastive along the fortis-lenis divide supported by the mICM. The contrasts they analyse 
stem from the voiceless-voiced divide or do not always form proper minimal pairs. ${ }^{2}$ Fricatives are the best example of such a situation. As it was mentioned before, /f/ and /v/ and $/ \theta /$ and / $/$ / are homorganic and contrastive as far as the laryngeal system is concerned, whether we from the fortis-lenis or voiced-voiceless perspective. However, phonologically speaking, in Welsh, /v/ is contrastive to $/ \mathrm{m}, \mathrm{b} /$ word-finally (see Asmus and Grawunder 2017). ${ }^{3}$ Word-initially, it does not normally occur in native lexemes, unless mutated and is then contrastive to $/ \mathrm{m}, \mathrm{b} /$ as well. The minimal pairs such as $y$ ffordd 'road (Old English borrowing)' and $y$ ford 'table (Old English borrowing, mutated)' that may be presented in order to suggest a /f/ and /v/ contrast are normally borrowings. As a result, they may establish a gateway into Welsh for such a contrast by allowing to affect other sounds along the voiceless-voiced pronunciation leading to changes in Welsh phonology.

For $/ \theta /$ and $/ ð /$ there seem to be minimal pairs such as gwyrth 'miracle (Latin borrowing)' and gwyrdd 'green (Latin borrowing)', moth 'moth (English borrowing)' and modd 'mode (Latin borrowing)', or, if one decides to focus on the words of native origin, bydd 'she/he will' and byth 'never/ever'. However, Asmus and Grawunder (2017) show that relative length can be observed here, making it difficult to establish a clear contrast. In addition, the two sounds are not contrastive in English, so its influence on Welsh should remain limited. ${ }^{4}$

Analysing truly phonologically contrastive pairs of sounds offers promising perspectives and when it comes to the Welsh fricative, /s/ versus /h/ constitutes such pair, but this issue is omitted both in Jones and Ball. Even though it is not actively employed in the Welsh mICM, there are certain minimal pairs, for instance sil 'seed' and hil 'breed', that reflect such a contrast. Moreover, it is well-rooted in another Insular Celtic language, i.e. Irish. Also, Asmus and Grawunder (2018) show that it is contrastive word-finally in Welsh, for instance in rhy 'too' and rhys 'embers', plas 'palace' and pla 'plague' or lles 'benefit' and lle 'space'.

Hannahs (2013) uses the voiceless-voiced terminology but is aware of the phonetic research by Ball (1984). His descriptions prove that if one uses the fortis-lenis distinction in such a way, i.e. as a synonym for the voiceless-voiced distinction then, in essence, there is no effect of this new terminology. Using the fortis-lenis distinction appears to be decisive and influential only if it leads to establishing different minimal pairs than the ones based on the voiceless-voiced distinction.

Asmus and Grawunder (2017) revealed that there is a clear correlation between vowel and coda length in Welsh monosyllables along the fortis-lenis divide. ${ }^{5}$ The fortis-lenis divide is there understood in this radical sense that results in having different minimal pairs. The aforementioned minimal pair/s/ vs /h/, omitted in the voiceless-voiced or the quasi fortis-lenis

2 For instance, the minimal pair of hoff 'dear' and hof 'hoe' is not a proper one because the latter lexeme is 1) an English borrowing and 2) rarely used. There are also some minimal pairs which present consonants in clusters, for instance corf 'pommel' and corff 'mass'. Since this paper is focused on consonants found in simplex codas and onsets of monosyllables, such examples go beyond its scope.

3 An example of such a minimal pair is tref 'town' and trem 'sight'.

4 I would like to thank dr hab. Sabine Asmus, prof. US (Szczecin, Leipzig) for having pointed this issue out to me as well as advised on the $/ \mathrm{s} /$ and $/ \mathrm{h} /$ distinction and provided me with minimal pairs from unpublished material.

5 This kind of vowel-coda dependence has been studied by many researchers, for instance Chen (1970), Hogan and Rozsypal (1980) or Lisker (1986). 
distinction, proves to be as decisive as /p/ vs /b/ when it comes to vowel and coda length. Contrary to common assumption, it is the consonant length which determines that of the preceding vowel, thus identifying Welsh as a consonant-driven language.

\subsection{Theoretical reasons for parameter selection}

This section introduces the parameters that were measured in this study. As aforementioned, the approach here is that the fortis-lenis distinction hinges upon four features: peak glottal aperture, articulatory timing, voicing and aspiration. All of them, apart from peak glottal aperture, were taken into consideration. Articulatory timing was linked with friction length for fricatives and hold phase duration and aspiration length for plosives. Voicing was measured both for fricatives and plosives. Understandably, aspiration was only measured for plosives. The aforementioned features are briefly defined in the following paragraphs and the reasons for their selections are explained.

Phonetic voicing is the first of the features under review and it was measured for both fricatives and plosives. Trask (1996: 381) defines it as vocal folds vibration happening while articulating a given sound and claims that it may be the one parameter that distinguishes between voiced and voiceless sounds. Even though Ball (1984) and Asmus and Grawunder (2017) suggest that the influence of phonetic voicing in Welsh is incidental at most, it should still be included in any study focused on laryngeal systems.

Aspiration, the second feature under review, is defined as "a period of voiceless breathing", that follows an obstruent (Trask 1996: 36; Stevens 1998: 451). For experimental phonetics, aspiration is friction following the release of a plosive. It is connected with the voice-onset time (abbreviated to VOT), i.e. the time between the release of the plosive to the beginning of modal voicing signifying a vowel. Since it is assumed here that Welsh is an aspirating language, this feature definitely has to be studied. Diachronically speaking, aspiration, together with general articulation length, is seen to have been decisive for the distinction between the radical fortis plosives, lenited fortis plosives and radical lenis plosives observable in Old and Middle Welsh before the lenited fortis plosives blended with the radical lenis ones forming the system known from Modern Welsh (Sybren van Sluis 2019: 75).

The third factor under review, relevant only for plosives, is the hold phase duration, also called approach. In citation forms or after a pause, $/ \mathrm{p}, \mathrm{t}, \mathrm{k} /$ are said to feature a longer hold phase than /b, d, g/, but the differences are not evident in connected speech (Ogden 2009: 98). Hold phase duration is here seen as one of the articulatory timing features and as such seems to be worth measuring because of the apparent vowel-coda duration dependence discovered by Asmus and Grawunder (2017).

The fourth factor is friction length which may be seen as an equivalent of aspiration for fricatives. Studying the friction to voice ratio offers similar potential results as the VOT. Measuring friction length also contributes to an in-depth study of the articulatory timing which as claimed in the previous paragraph, seems to be quite relevant for the distinction between fortis-lenis Welsh obstruents. 


\section{The study}

\subsection{Methodology and the participants}

Both of the studies to be discussed here were conducted on the same set of recordings. The first study focused on plosives (Asmus et al. 2019) and the second one dealt with fricatives (Baran 2020). 31 native speakers, male and female aged 19-71, mostly from North Wales ${ }^{6}$, who use their language at home and at work, were interviewed between 2013 and 2018. The average age of participants was 58 and the majority of them were female. As far as education is concerned, they were mostly educated standard speakers. The analysis was undertaken both in the onset and coda of monosyllabic native lexemes currently in use. The lexemes were taken from previous corpora (Asmus and Grawunder 2017) but were further amended by adding more lexemes to cover more sounds. The tokens were then placed in the carrier phrase $D w i$ heb ddweud (1) ond (2)! 'I didn't say (1) but (2)!' and were ordered in a way that every lexeme appears in the recording twice in a strong and twice in a weak prosodic position. Selected native lexemes were also recorded in normal sentences. Then, the target items were analysed with the help of the Praat software (Boersma and Weenink 2019).

In the analysis of plosives, the holding phase duration ${ }^{7}$ (potential voicing) and aspiration were measured. It was assumed that aspiration is a period of friction extending from the release of a plosive to the onset of modal voicing. Knowing that friction following an initial lenis plosive may be partially voiced, both parameters were measured in order to establish whether their relative durations distinguish fortis plosives from their lenis counterparts. The collected data were subjected to a statistical analysis by means of a mixed-design ANOVA, which takes into consideration the influence of random effects, which include speakers and the phonological contexts.

As far as fricatives are concerned, friction and voicing length were measured. In wordinitial sounds, friction length was measured from the point where the voicing of the preceding sound / $\mathrm{d} /$ ceased to the beginning of modal voicing. Voicing length was measured from the first occurrence within the friction phase to the end of the friction phase. In word-final position, friction length was measured from the point where the modal voicing ceased to the point where the friction phase finished or where the following sound has clearly begun. The collected temporal data were subjected to the same type of statistical analysis as plosives.

\subsection{Results}

The analysis of aspiration and voicing length was conducted separately in the word-initial and word-final position. In word-initial position aspiration and voicing length were measured,

6 There were only two South Welsh speakers which made it impossible to draw any conclusions regarding dialectal differences.

7 Due to the phonetic nature of the carrier phrase the holding phase duration could only be measured accurately in the word-final position. 
while in word-final position, hold phase was added to the two aforementioned features. The table below presents the results of the analysis conducted in word-initial position. ${ }^{8}$

Table 2: Aspiration and voicing length in the word-initial position

\begin{tabular}{l|cc|cc}
\hline & \multicolumn{2}{|c|}{ ASPIRATION } & \multicolumn{2}{c}{ VOICING } \\
\hline & Average & Standard deviation & Average & Standard Deviation \\
$/ \mathrm{p} /(1)$ & 117.6 & 24.5 & 13.6 & 2.4 \\
$/ \mathrm{p} /(2)$ & 90.3 & 16.6 & 14.2 & 2.2 \\
$/ \mathrm{t} /(1)$ & 129.3 & 34.6 & 12.2 & 2.1 \\
$/ \mathrm{t} /(2)$ & 113.4 & 20.7 & 16.9 & 3.3 \\
$/ \mathrm{k} /(1)$ & 148.2 & 41.4 & 13.5 & 1.9 \\
$/ \mathrm{k} /(2)$ & 138.6 & 25.8 & 13.8 & 3.1 \\
$/ \mathrm{b} /(1)$ & 19.9 & 3.1 & 11.3 & 2.8 \\
$/ \mathrm{b} /(2)$ & 17.3 & 3.1 & 9.5 & 2.5 \\
$/ \mathrm{d} /(1)$ & 22.8 & 4.2 & 12.1 & 2.5 \\
$/ \mathrm{d} /(2)$ & 21.8 & 4.6 & 13.7 & 3.1 \\
$/ \mathrm{g} /(1)$ & 33.4 & 3.7 & 13.8 & 3.6 \\
$/ \mathrm{g} /(2)$ & 33.4 & 5.1 & 17.1 & 4.4 \\
\hline
\end{tabular}

It appears that the two series of sounds differ strongly in terms of aspiration length. The difference is visible while comparing homorganic pairs of sounds but also while looking at the fortis and lenis series as groups. As far as voicing is concerned, voicing length is not always conclusive and the differences both between homorganic pairs of sounds and the fortis and lenis series are at best slight.

Table 3: Hold phase, aspiration and voicing length in the word-final position

\begin{tabular}{l|cc|cc|cc}
\hline & \multicolumn{2}{|c|}{ HOLD PHASE } & \multicolumn{2}{c|}{ ASPIRATION } & \multicolumn{2}{c}{ VOICING } \\
\hline & Average & $\begin{array}{c}\text { Standard } \\
\text { deviation }\end{array}$ & Average & $\begin{array}{c}\text { Standard } \\
\text { deviation }\end{array}$ & Average & $\begin{array}{c}\text { Standard } \\
\text { deviation }\end{array}$ \\
$/ \mathrm{p} /(1)$ & 208.2 & 39.8 & 119.6 & 27.7 & 17.4 & 3.1 \\
$/ \mathrm{p} /(2)$ & 157.3 & 20.2 & 82.4 & 19.4 & 24.6 & 5.9 \\
$/ \mathrm{t} /(1)$ & 203.6 & 46.3 & 124.7 & 39.4 & 13.4 & 2.4 \\
$/ \mathrm{t} /(2)$ & 177.8 & 26.4 & 96.9 & 22.5 & 19.2 & 6.8 \\
$/ \mathrm{k} /(1)$ & 226.9 & 49.5 & 142.6 & 40.8 & 16.1 & 2.6 \\
$/ \mathrm{k} /(2)$ & 195.7 & 34.4 & 120.1 & 28.8 & 17.3 & 2.7 \\
$/ \mathrm{b} /(1)$ & 96.2 & 28.9 & 66.8 & 25.4 & 21.2 & 5.3 \\
$/ \mathrm{b} /(2)$ & 74.6 & 13.7 & 47.3 & 18.6 & 22.7 & 7.8 \\
$/ \mathrm{d} /(1)$ & 109.5 & 38.7 & 89.6 & 19.7 & 20.4 & 4.6 \\
$/ \mathrm{d} /(2)$ & 83.4 & 14.2 & 56.6 & 17.1 & 29.4 & 6.3 \\
$/ \mathrm{g} /(1)$ & 123.3 & 42.2 & 95.9 & 22.3 & 22.1 & 3.9 \\
$/ \mathrm{g} /(2)$ & 97.3 & 15.6 & 66.2 & 17.9 & 40.1 & 7.2 \\
\hline
\end{tabular}

The analysis of the word-final plosives reveals a similar pattern to the word-initial position, where voicing is not decisive in distinguishing between the two series of sounds under review.

\footnotetext{
8 In this and the following tables (1) means the first position in the carrier phrase and (2) means the second position in the carrier phrase.
} 
The differences in voicing vary from situations like /p/ (2) vs /b/ (2) where it is the fortis sound that has more voicing on average, to significantly longer voicing period in the lenis sound as in /g/ (2) vs / k/ (2). The other two parameters, i.e. aspiration and hold phase, appear to be more reliable with significantly longer periods of aspiration and longer hold phases in articulation of the fortis sounds.

In brief, analysing plosives in word-initial and word-final position suggests that voicing is not enough to distinguish between the fortis and lenis sounds in the Welsh language. Alternative measurements such as aspiration length and hold phase duration exhibit a clearer and more reliable pattern.

The analysis of fricatives was also conducted word-initially and word-finally, but regardless of the position the same two parameters were measured, i.e. friction and voicing length. However, because of distributional restrictions the sounds under review were not the same in the two positions under review. The table below presents the results of the word-initial analysis of $/ \mathrm{s}, \mathrm{f}, \mathrm{h}, \mathrm{v} /$.

Table 4: Friction and voicing length in the word-initial position

\begin{tabular}{l|cc|cc}
\hline & \multicolumn{2}{|c|}{ FRICTION } & \multicolumn{2}{c}{ VOICING } \\
\hline & Average & Standard deviation & Average & Standard deviation \\
/s/ (1) & 198.8 & 50.3 & 10.5 & 4.6 \\
/s/ (2) & 207.6 & 63.2 & 11.4 & 6.5 \\
/f/ (1) & 179.2 & 56.4 & 10.9 & 13.3 \\
/f/ (2) & 195.8 & 65.6 & 13.7 & 8.2 \\
/h/ (1) & 140.4 & 52.6 & 37.2 & 43.7 \\
/h/ (2) & 148.1 & 69.1 & 38.4 & 46.7 \\
/v/ (1) & 123.2 & 55.8 & 76.4 & 76.6 \\
/v/ (2) & 119.4 & 48.5 & 90.5 & 71.5 \\
\hline
\end{tabular}

The two series of sounds appear to significantly differ in terms of both friction and voicing length. It is worth to note that the homorganic pair /f/ vs /v/ established on the basis of the laryngeal system only exhibits the same pattern as the phonologically motivated $/ \mathrm{s} / \mathrm{vs} / \mathrm{h} /$. The voiceless-voiced distinction that views both $/ \mathrm{s} /$ and $/ \mathrm{h} /$ as voiceless sounds would not be able to account for the observed differences in articulatory timing.

Table 5: Friction and voicing length in the word-final position

\begin{tabular}{l|cc|cc}
\hline & \multicolumn{2}{|c|}{ FRICTION } & \multicolumn{2}{c}{ VOICING } \\
\hline & Average & Standard deviation & Average & Standard deviation \\
/f/ (2) & 262.2 & 79.1 & 35.0 & 15.1 \\
$/ \theta /(1)$ & 246.1 & 100.6 & 37.1 & 25.6 \\
$/ \theta /(2)$ & 262.0 & 76.8 & 37.1 & 16.9 \\
/v/ (1) & 231.7 & 89.2 & 52.6 & 23.0 \\
/v/ (2) & 166.2 & 43.2 & 70.8 & 29.7 \\
$/$ / / (1) & 163.1 & 79.5 & 57.8 & 41.7 \\
$/$ / / (2) & 156.3 & 56.5 & 52.4 & 18.3 \\
\hline
\end{tabular}


In the word-final position the analysis focused on $/ f, \theta, v, \partial /$. These sounds constitute two homorganic pairs, which are not supported by the mICM system, but the pattern is still visible. The fortis sounds have considerably longer friction periods than their lenis counterparts and in all instances under review this parameter distinguished between the two series correctly. As far as voicing is concerned, the general tendency is that the lenis sounds have more voicing, but in some instances such as $/ \theta /(2)$ vs /ð/ (2) the differences are slight and depending on a speaker may not result in correct differentiation between the series.

To sum up, the analysis of fricatives suggests that voicing is mostly helpful in distinguishing between the fortis and lenis series, but friction length proved to be distinctive for all the fricatives under review both in word-initial and word-final position.

\section{Discussion}

In order to reconcile the results of the two studies summarised here, one ought to focus on two groups of features, i.e. voicing and other aspects of articulatory timing such as friction, aspiration or hold phase. The analysis of voicing suggests that it is not a feature that would always be sufficient to distinguish between the fortis and lenis series. In the case of plosives, it proves to be only incidentally decisive while it can also be inconclusive or misleading. In fricatives, voicing differences are clearly visible for $/ \mathrm{f} /$ and $/ \mathrm{v} /$, but are not fully conclusive for $/ \theta /$ and $/ \partial /$. Because of all that it seems that the phonetic voicing in articulation of the Welsh fricatives and plosives placed word-initially and word-finally in monosyllables is not distinctive for the fortis-lenis distinction.

The remaining three phonetic features, i.e. friction, aspiration and hold phase duration are analysed together, because they are all directly linked to the general duration of a sound. Voicing does not influence the general length of a consonant in such a direct way, because it occurs within aspiration or friction period. Moreover, there is a similarity between friction and aspiration, as aspiration is friction that appears after the release of the plosive. The analysis undertaken in the two studies summarised here suggests that these features are more reliable while distinguishing between the fortis and lenis sounds. Aspiration proves to be conclusive in all instances of plosive contrast under review and so does the hold phase. Friction length forms a stable paradigm throughout all instances of fricatives contrast under review. These observations support the point that the Welsh fortis-lenis laryngeal system is phonetically realised through articulatory timing and consonantal length. Depending on the manner of articulation the difference is visible either in aspiration and hold phase length in plosives or friction length in fricatives. Generally, there seems to be a pattern of the fortis obstruents being longer than their lenis counterparts.

\section{Conclusions}

This paper builds on the following findings of research on laryngeal systems: 1) for some languages, the fortis-lenis distinction is more appropriate than the voiceless-voiced distinction 2) the aforementioned phonological distinctions may be indicated by various phonetic features, 
with the most common associations being the ones between phonetic voicing and [voice] and aspiration and [spread glottis] and 3) the same phonological feature may be responsible for the distinction between the series of sounds regardless of the manner of articulation, but its phonetic realisation may vary language-specifically.

Phonological research on the Welsh consonants suggests that it is one of the languages that employ the fortis-lenis contrast and that the phonetic voicing is of limited importance to it. The aim of this paper was, therefore, to verify it experimentally by studying Welsh obstruents. The plosives /p, b, t, d, k, g/ and fricatives /f, $\theta, \mathrm{v}, \mathrm{\partial}, \mathrm{s}, \mathrm{h} /$ were studied in monosyllabic lexemes in word-final and word-initial position. Aspiration, hold phase and voicing for plosives and friction and voicing for fricatives were measured in order to decide whether these factors are phonetically relevant in the fortis-lenis distinction of the Welsh obstruents.

The analysis confirmed that voicing is not fully conclusive when it comes to Welsh obstruents. The correlation was somewhat weak in plosives and slightly stronger in fricatives. Other aspects of articulatory timing proved decisive and formed clear correlations in all contrasts under review regardless of manner of articulation, position, prosodic position or place of articulation. These findings appear to support the fortis-lenis distinction of the Welsh obstruents and to disprove the voiceless-voiced one. The most important feature in the fortislenis distinction appears to be the articulatory timing - the fortis sounds seem to be longer than their lenis counterparts.

\section{References}

Asmus, S. and S. Grawunder. 2017. Vowel length in Welsh monosyllables - Consonant-mutation dependence, Irish cognation and related theoretical problems. An acoustic study and its didactic implications. Lampeter: The Edwin Mellen Press.

Asmus, S., and S. Grawunder. 2018. Language-structuring consonant mutation(s) in Welsh (and Irish). https://www.academia.edu/33509077/Language_structuring_consonant_mutation_s_in_Welsh_and_Irish_

Asmus, S., S. Jaworski, and M. Baran. 2019. Fortis-lenis of voiced-voiceless - Features of Welsh consonants. In S. Calhoun, P. Escudero, M. Tabain and P. Warren (eds.), Proceedings of the 19th International Congress of Phonetic Sciences, Melbourne, Australia 2019, 3773-3776. Canberra: Australasian Speech Science and Technology Association Inc.

Ball, M. J. 1984. Phonetics for phonology. In M. J. Ball and G. E. Jones (eds.), Welsh phonology. Selected readings, 5-39. Cardiff: University of Wales Press.

Ball, M. J., and B. Williams. 2011. Welsh phonetics. Lewiston: The Edwin Mellen Press.

Baran, M. 2020. Friction and voicing length as phonetic correlates in the fortis-lenis distinction of the Welsh fricatives. Proceedings of the Association of Celtic Students of Ireland and Britain Vol. VII: 69-91.

Baran, M., and S. Asmus. 2019. A new perspective on Welsh and Irish consonant mutations. In S. Asmus and K. Jaworska-Biskup (eds.) New perspectives on Modern Wales - Studies in Welsh language, literature and social politics, 157-177. Cambridge: Cambridge Scholars Publishing.

Boersma, P., and D. Weeink. 2019. Praat: Doing phonetics by computer [computer programme]. Version 6.1.08.

Butcher, A. 2004. Fortis-lenis revisited one more time: The aerodynamics of some oral stop contrasts in three continents. Clinical linguistics and phonetics 18: 547-557.

Chen, M. 2017. Vowel length variation as a function of the voicing of consonant environment. Phonetica 22: 129159.

Cyran, E. 2011. Laryngeal realism and laryngeal relativism: Two voicing systems in Polish? Studies in Polish Linguistics 6: 45-80.

Hannahs, S. J. 2013. The phonology of Welsh. Oxford: Oxford University Press. 
Hardcastle, W. J. 1973. Some observations on the tense-lax distinction in initial stops in Korean. Journal of Phonetics 1: 263-272.

Hogan, J. T., and A. J. Rozsypal. 1980. Evaluation of vowel duration as a cue for the voicing distinction in the following word-final consonant. Journal of the Acoustic Society of America 67: 1764-1771.

Honeybone, P. 2005. Diachronic evidence in segmental phonology: The case of obstruent laryngeal specifications. In M. van Oostendorp, and J. van de J. Weijer (eds.), The internal organization of phonological segments, 319354. Berlin: Mouton de Gruyter.

Jaeger, J. J. 1983. The fortis/lenis question: Evidence from Zapotec and Jawon. Journal of Phonetics 11: 177-189.

Jakobson, R., G. M. Fant, and M. Halle. 1951. Preliminaries to speech analysis: The distinctive features and their correlates. Cambridge: MIT Press.

Jones, G. E. 1984. The distinctive vowels and consonants of Welsh. In M. J. Ball and G. E. Jones (eds.), Welsh phonology. Selected readings, 40-64. Cardiff: University of Wales Press.

Ladefoged, P. 1989. Representing phonetic structure. UCLA Working Papers in Phonetics 73: 1-79.

Lisker, L. 1986. 'Voicing' in English: A catalogue of acoustic features signaling /b/ versus /p/ in trochees. Language and Speech 29: 3-11.

Malécot, A. 1970. The lenis/fortis opposition: Its physiological parameters. Journal of the Acoustic Society of America 47: 1588-1592.

Odgen, R. 2009. An introduction to English phonetics. Edinburgh: Edinburgh University Press.

van Sluis, P. S. 2019. Lenited voiceless stops in Middle Welsh: Phonology and orthography. An unpublished PhD thesis. University of Wales.

Stetson, R. H. 1951. Motor phonetics. Amsterdam: North Holland.

Stevens, K. N. 1998. Acoustic phonetics. Cambridge: MIT Press.

Trask, R. L. 1996. A dictionary of phonetics and phonology. New York: Routledge. 